\title{
FORMAÇÃO CONTINUADA E SUJEITOS-PROFESSORES: DISCURSOS E IDENTIDADES
}

\author{
IN-SERVICE EDUCATION AND SUBJECT TEACHERS: DISCOURSES AND \\ IDENTITIES
}

\author{
Fernanda A. Chuffi \\ Universidade de São Paulo \\ Filomena Elaine P. Assolini \\ Universidade de São Paulo
}

\begin{abstract}
RESUMO: Investigamos os processos formativos de sujeitos-professores ( $1^{\circ}$ ao $5^{\circ}$ ano) e as repercussões desses processos para a (des)construção de suas identidades profissionais. O aparato teórico é constituído pela Análise de Discurso (Pêcheux), em que o discurso é objeto histórico, e mantém sempre relação com outros dizeres. Trazemos a Psicanálise freudo-lacaniana, que pressupõe um sujeito atravessado pelo inconsciente, constituído pela falta e pelo(s) outro(s). As Ciências da Educação embasam as experiências formativas continuadas pelos quais o sujeito-professor passa e os ecos dessas para sua vida pessoal e profissional. Constituímos o corpus a partir de depoimentos escritos dos professores, nos quais discorrem sobre suas experiências de formação continuada. Selecionamos algumas, SDR (Courtine,1981), e observamos que: 1) há controle dos sentidos que podem circular nesses cursos, de modo que os sujeitos-professores são censurados e interditados em seus dizeres e fazeres pedagógicos e muitas vezes ocupam a posição de enunciadores de discursos alheios, reproduzindo, sem análise crítica alguma, as práticas pedagógicas que lhes são apresentadas tomando-as como modelos irrefutáveis; 2) os professores são imaginados como sujeitos, cujas identidades seriam fixas, estáveis, inabaláveis. Constituídas a partir de múltiplas vozes e sentidos, as identidades estão em constante processo de (re)construção e (re)significação, sendo afetadas por toda sorte de experiências vivenciadas pelo sujeito.
\end{abstract}

PALAVRAS-CHAVE: Formação, Professores, Discurso, Identidades.

ABSTRACT: This work investigates in-service education of subject-teachers in Elementary school (teaching 6 to 10 year-olds) and the implications of this process for the (de)construction of their professional identity. This investigation adopts the perspective of Pechêux's French Discourse Analysis, in which discourse is a historical object, always is relationship with other wordings. We also bring Lacan's perspective on Freudian psychoanalysis, which understands the subject as pervaded by the unconscious, established upon lacking and by/with the $(0)$ ther(s). The in-service Education experience which the subject-teacher goes through in the personal life and teaching career is investigated by means of Teaching-Learning theories. Our sample is formed with transcribed excerpts of interviews with teachers describing their experience in in-service education. From the selected excerpts and discursive sequences of reference (Courtine, 1981), we observe that: 1) there is some control of the meanings allowed to circulate in those courses. Subject-teachers tend to censor and control their wordings and doings within their teaching, and many times assume someone else's discourse, reproducing teaching methods uncritically, taking them as unquestionable; 2 ) teachers are imagined as subjects with fixed, stable and unshakable identities. However, we understand identities are formed with 


\section{Revista do SELL}

v. 6 , no. 3

ISSN: $1983-3873$

multiple voices and meanings, in constant (re)construction and (re)signification, affected by all kinds of experiences the subject goes through.

KEYWORDS: Teacher education, discourse, identities.

\section{INTRODUÇÃO}

(...) Eu não comando as minhas palavras... as palavras me elaboram (Manoel de Barros)

Partindo da epígrafe e da metáfora sobre comandar as palavras, ser elaborado por elas ou até mesmo elaborá-las, pensamos nas formações de professores (inicial/continuada), espaços em que circulam as palavras, os discursos, as teorias, as concepções institucionais junto ao processo singular do sujeito-professor.

Cursos esses que podem ilhar, prender ou libertar os sujeitos-professores. Assim, é fundamental entendermos quais as relações que os sujeitos-professores estabelecem com as propostas e perspectivas proferidas nas formações institucionais, oferecidas pelo município de Ribeirão Preto, SP, no intuito de entender se tais palavras, teorias e práticas os (re)elaboram.

Apresentamos resultados parciais de uma pesquisa que investiga como os cursos de formação continuada são discursivizados (tratados, imaginados e falados) por sujeitosprofessores do ensino fundamental I (do $1^{\circ}$ ao $5^{\circ}$ ano).

O interesse por esse tema nasceu a partir da preocupação sobre a difusão e a profusão dos cursos de formação continuada que são oferecidos a sujeitos-professores pelos órgãos de ensino. Nossas inquietações instigam-nos a problematizar esses cursos, mais especificamente a entender o que pensam os sujeitos-professores, a partir das vivências e experiências nessas situações de aprendizagem que, segundo mostra-nos a literatura a respeito, nem sempre entende o sujeito-professor como aquele que possui conhecimentos e experiências profissionais acumuladas.

Outra questão problematizadora que envolve tais eventos é a tentativa desses de preencher as lacunas deixadas pela formação inicial, pressupondo um sujeito sem condições de dominar os conteúdos, metodologias e práticas de ensino.

Sendo assim, temos o propósito de compreender como esses cursos são pensados e discursivizados pelos sujeitos-professores, visto que partimos do pressuposto segundo o qual os cursos de formação continuada interferem no desenvolvimento profissional e na construção das identidades profissionais docentes. 


\section{Revista do SELL}

v. 6 , no. 3

ISSN: $1983-3873$

Para alcançar nosso objetivo valer-nos-emos da Análise de Discurso de Matriz Francesa (AD) (Pêcheux,1969); Orlandi 1996, 2005, de alguns fios da psicanalise freudolacanaina e das contribuições de estudiosos que se dedicaram à área de formação de professores como Imbérnom (2010) e Nóvoa (2004).

Organizamos este artigo em quatro diferentes e interligados espaços. Num primeiro momento, apresentaremos o aparato teórico, no segundo momento, nos deteremos nos aspectos metodológicos, apresentando como se constituiu a nossa pesquisa. Numa terceira etapa, entraremos num espaço analítico trazendo os recortes, as análises discursivas e os gestos de interpretação, para então alinhavarmos possíveis gestos de interpretação com as considerações finais.

\section{FUNDAMENTOS CENTRAIS DA ANÁLISE DE DISCURSO FRANCESA}

Trabalharemos com o campo teórico-metodológico da Análise de Discurso francesa (doravante $A D$ ), ressaltando seu objeto de estudo, o discurso em movimento, em percursos que se (re)fazem no correr entre as línguas nos efeitos de sentido entre interlocutores (Pêcheux:1969), e, assim, definimos esses efeitos como os indícios que se constituem no processo de interlocução em que estão presentes as relações de força estabelecidas e determinadas sócio-historicamente, entre os fazeres científicos, profissionais, cotidianos e as histórias individuais que compõem cada sujeito.

Nessa perspectiva do movimento, trazemos o discurso como o conceito intermediário que se coloca no lugar em que se encontram tanto a manifestação da liberdade do locutor (resistência) quanto a ordem da língua (ideologia), enquanto sequência sintaticamente correta (Orlandi, 1996, p.193), compreendendo o discurso enquanto efeito na/da posição de sujeito discursivo, em que o sujeito não é tido como um indivíduo passível de regularidade, categorizações, nem é quantificável, mas assenta-se em lugares inscritos no dizer e posições de/à linguagem.

Uma vez com predisposição para analisar a linguagem em movimento(s) de sentido(s), temos as marcas da ideologia nas relações que os sujeitos trazem e fazem com as palavras, de acordo com as posições que os mesmos ocupam, uma vez que "não há discurso sem sujeito nem sujeito sem ideologia" (Orlandi, 2003, p.13), assim, enquanto efeito de linguagem, o sujeito traz em seu discurso os ecos de sua posição docente, de suas identificações, de suas identidades que poderão atualizar ou reverberar na memória 


\section{Revista do SELL}

v. 6 , no. 3

ISSN: $1983-3873$

discursiva pelos efeitos de um já-dito, trazidos pelas formações discursivas com as quais o sujeito se identifica.

A memória discursiva é trazida nesse percurso, pois o saber discursivo torna possível o dizer "que retorna sob a forma do pré-construído... sustentando cada tomada de palavra" (Orlandi, 2005, p.31), assim o interdiscurso é o efeito evocado, que afeta e disponibiliza modos de como o sujeito pode se (re)significar a partir de determinadas situações e/ou posições discursivas.

Nesse processo de (re)significação do discurso, a ideologia faz parecer evidente que certos sentidos sejam ditos, apagando outros impossíveis de circular. Dessa maneira, a ideologia produz uma relação necessária de obviedade para o sujeito em determinada posição. Ao mudar de posição, a ideologia interpela o sujeito de outro modo, o que nos permite considerar que o sujeito pode migrar, mover-se entre diversas regiões de sentido, deslocar-se de uma formação discursiva para outra, construir o seu dizer, de acordo com a posição de poder e saber que ocupa.

Tendo em vista as considerações acima, pretendemos conduzir nossa pesquisa compreendendo a linguagem em sua incompletude, para além da gramaticalização e da documentação repetitória, as quais são tão vivenciadas no contexto escolar, abrindo espaços para outras práticas mais desafiadores e inquietantes. A sala que compõe a formação continuada é para nós um lugar privilegiado da escuta desse jogo discursivo, pois permite questionar sentidos naturalizados, no nosso caso, tidos como lei. E, ao questionar na posição de analistas podemos entender as situações e as posições que o sujeitoprofessor ocupa diante de algumas normatizações e repetições.

Quando pensamos em AD, necessariamente nos remetemos à necessidade dos sentidos, pois, o sujeito do discurso produz sentidos para si e para os outros. Suas relações se dão nos processos discursivos, assim sendo, o sujeito se filia, seja para se posicionar, para falar de si, sobre si e/ou sobre os outros. Nesse processo de filiações, o sujeitoprofessor demonstra as marcas de suas relações de identificações com os outros.

Concebemos, então, o sujeito do discurso como o sujeito da linguagem que significa e é significado de acordo com as posições que ocupa, em que o discurso não se confunde com o texto, porém, percorre, perpassa, atravessa e se filia a momentos históricos, trazendo à tona o funcionamento, o movimento, o deslocamento, a repetição, de acordo com a condição de produção à qual está inserido. O discurso se dá entre locutores, e pelas constituições dos sentidos que podem ser múltiplas. 


\section{Revista do SELL}

v. 6 , no. 3

ISSN: $1983-3873$

Nas perspectivas das formações discursivas, o conceito de condições de produção se torna importante e, segundo Assolini (2013, p.34), "podem ser entendidas como sendo as circunstâncias em que se efetivam os discursos e se abarcam fundamentalmente os sujeitos, a situação e a memória", podemos, então, considerar o sentido estrito (enunciação) e/ou sentido amplo (contextos-históricos e ideológicos, memória discursiva, formação imaginária e memória institucional), assim, o discurso vai se tecendo e mantendo suas relações com outros dizeres.

Dando prosseguimento à apresentação dos postulados teóricos ainda nos interessa saber como o professor se posiciona em relação à memória institucional, qual imagem esse professor tem de si ou faz de si mesmo, lembrando também que o sujeito-professor é atravessado e assujeitado às lógicas do sistema educacional vigente, o que, muitas vezes, pode determinar a construção e legitimação do seu discurso enquanto profissional. Assim, outro conceito importante está relacionado à subjetividade, que é entendida como "(...) um lugar que o sujeito do discurso pode ocupar para falar de si, de suas experiências, conhecimentos de mundo, sentimentos, etc." (Tfouni, 1995, p.74).

O conjunto de representações que o sujeito faz de si e dos outros interfere na construção dos sentidos e das suas identidades, pois "toda formação discursiva dissimula, pela transparência de sentido que nela se constitui e pela sua dependência com relação do "todo complexo com dominante" das formações discursivas intricado no complexo das formações ideológicas. Pêcheux (1995, p.162)

Lembramos que esse é um gesto de interpretação dentre tantos outros possíveis, uma vez que "a discursividade é um acontecimento e nem a linguagem nem a história podem esgotar inteiramente - haverá sempre espaço para outro sentido, para outro discurso" (Gregolin, 2009, p.56). Sendo assim, dedicar-nos-emos, a partir de agora, a pensar algumas noções de processos formativos, formuladas por estudiosos que nos constituem ao longo de nossos estudos.

\section{O SUJEITO-PROFESSOR E ALGUNS CONCEITOS SOBRE OS PROCESSOS FORMATIVOS}

Sendo a docência pedagogicamente estruturada (Almeida, 2012), e os saberes de conteúdos importantes para a prática docente, trazemos reflexão em relação à formação continuada, uma vez que formar é mais que transmitir conteúdos, informações, e requer 


\section{Revista do SELL}

v. 6 , no. 3

ISSN: $1983-3873$

espaços de vivências, escutas, planejamentos, práticas, ações e trocas de acordo com a temática em questão.

Para isso, fomos ouvir dos próprios professores dentro desses espaços formativos, o que de fato acontece, uma vez que o termo "formação continuada" se contradiz com sua prática, e aponta a um espaço que se delimita em cursos de treinamentos, palestras, oficinas e seminários, presas a mecanismos de gerenciamento e não emergindo em sua prática efetiva e reflexiva democrática.

Nessa perspectiva, pensamos que o tema elegido assume-se como necessário nesse espaço social, político e ideológico acelerado, em que a formação configura-se em um binômio interativo (em relação aos alunos) e condicionado (em relação às raízes que constituem a história da educação).

Observamos, também, os reflexos da formação continuada institucionalizada, que é direcionada, é pensada em espaço de prioridade, pautados nas propostas pedagógicas das escolas, alicerçadas pelos contextos sociais e culturais e/ou de mudanças rápidas.

Buscamos, nas concepções de Nóvoa (2004, p.9), uma definição consistente sobre formação continuada, numa afirmação em que a formação necessita constituir-se em um "trabalho de pensar o trabalho".

Eu defendo que a formação contínua deve investir em três frentes: investir a pessoa e sua experiência, na valorização dessa experiência e não no desapossar dessa experiência; investir a profissão e os seus saberes, trabalhar os saberes que os professores já possuem; e finalmente o investir a escola e seus projetos.

Nesse processo "de pensar o trabalho", as formações continuadas precisariam valorizar e constituir-se num ir e vir de práticas, experiências e trocas, trazendo relações efetivas junto aos meios formativos dos sujeitos-professores, como possibilidades de interrelações subjetivas entre o que o professor é, fala e faz, dando a esse sujeito oportunidades de ocupar-se de outros e mais espaços, legitimando o seu saber e fazer. O autor aponta a necessidade de uma formação contínua pautada na perspectiva crítico-reflexiva, capaz de fornecer ao professor constituição autônoma, dinâmica, criativa com projetos próprios, trazendo assim, indicativos de novos desafios que superem o ensino centrado na transmissão de conteúdos disciplinares.

Ao construir ou constituir-se pelas delimitações impostas institucionalmente nas formações continuadas, o professor acaba apenas por (re)produzir, de forma convicta, 


\section{Revista do SELL}

v. 6 , no. 3

ISSN: $1983-3873$

práticas que não Ihe foram reflexivas, cristalizando sentidos e verdades que nem sempre são suas, tornando-se técnico e pragmático.

Na mesma proposta reflexiva do autor referido, trazemos para dialogar Nóvoa (2004) e Imbérnon (2010) com a afirmação de que, na formação continuada, há "muita formação e pouca mudança", demonstrando aqui o predomínio das políticas institucionalizadas de formação e formadores, marcando que há predomínio de uma teoria descontextualizada, muitas vezes transmissora e uniforme, fundamentada nas concepções e num educador que não existe, ou pelo menos não é real.

A formação continuada surge como se fosse capaz de (in)formar a produção de fazeres e as competências de cada professor, sempre enfatizando propostas que abarcam dimensão estrutural e desenvolvimento considerado global, através de resoluções simplificadas e unificadas, como se "as novas legitimidades fizessem descansar no(s) professor(es) a qualidade da educação" (Sacristán, 1998), o que compete a esses sujeitos é gerar e reproduzir "modelos" em suas práticas, dentro de um didatismo usurpador da autonomia pessoal e que fragmenta o fazer, a identidade, o posicionamento social e profissional.

Dentro dessa estrutura que formata a formação continuada, ainda hoje temos "a continuação de um trabalho isolado, no qual os professores não necessitam tratar com os demais, exceto nos processos burocráticos. Não existe diálogo sobre o que acontece, e a troca é fictícia" (Imbérnon, 2010, p. 68).

Nessa perspectiva apresentada até aqui, a formação continuada torna-se obsoleta e não se estabelece como parte intrínseca da profissão. Tais autores discutem o processo de formação dos professores tendo como ponto de partida o trabalho docente, o exercício de sua prática, as relações sociais que se estabelecem no contexto escolar, buscando rompimento com a racionalidade técnica proposta até então nesses cursos que privilegiam as práticas em detrimento de um trabalho unificado entre teorias e práticas.

Ainda nessa linha de transformação dos processos da formação continuada, mobilizamos Tardif $(2002$, p.9) que marca que "um professor de profissão não é somente alguém que aplica conhecimentos produzidos pelos outros, não somente um agente determinado por mecanismos sociais, mas sim é um sujeito que assume sua prática a partir dos significados que ele mesmo Ihe dá". O sujeito-professor então, nessa perspectiva, é alguém que organiza suas experiências de vida, sua história, seus valores, sua afetividade e age de acordo com sua construção social e pessoal. 


\section{Revista do SELL}

v. 6 , no. 3

ISSN: $1983-3873$

O autor ainda afirma que “... reconhecer que os professores de profissão são sujeitos do conhecimento é reconhecer, ao mesmo tempo, que deveriam ter direito de dizer algo a respeito de sua própria formação profissional, pouco importa que ela ocorra na universidade, nos institutos ou em qualquer outro lugar".

Por isso, a formação continuada, enquanto espaço de reflexão, discussões coletivas, confluências e perspectivas, se dá no confronto e nas relações de poder, fazendo emergir novas competências no processo de formação e profissionalização, criando outros perfis/identidades.

A participação do professor no processo de formação continuada, enquanto sujeito produtor de saberes e propostas, constitui e legitima um lugar que é seu, conferindo-lhe sensação de pertencimento e de produtor de conhecimentos.

Nessa posição semanticamente estabilizada e fornecida pela formação continuada, há pressupostos marcados de que, ao se tornar consumidor, o sujeito-professor recebe as construções prontas de saberes, muitas vezes se tornando passivo e obsoleto a essas formações oferecidas institucionalmente. Pensando nessa posição de consumidor do saber, Nóvoa (2004) afirma que, no momento em que os próprios professores não realizam o trabalho e pensam o seu trabalho, essa tarefa é executada por outros e, nesse caso, os professores passam a ser meros executores de coisas concebidas e pensadas pelos outros.

Está pesquisa busca puxar esses fios da memória do professor numa perspectiva em que a memória não se restitui em frases escutadas no passado, mas de julgamentos verossímeis que deslocam o sujeito a uma posição discursiva enunciativa, pois a memória suposta pelo discurso é sempre (re)construída na enunciação. Assim, a memória é tudo aquilo que deixa marcas nos tempos desjuntados que vivemos e que nos permite a todo momento reunir e emergir temporalidades passadas, presentes e por vir (Pêcheux, 1995).

Assim, nos interessa entender como foram sendo construídas e constituídas as identidades dos sujeitos-professores, permeados pela memória que se (re)faz dentro do percurso profissional, ultrapassando as concepções reducionistas que constituem a maioria das formações continuadas, focando no professor como um sujeito, não dono do saber, mas aquele que troca saberes, que se estabelece nas relações ensino-aprendizagem, que tem voz, que faz seu percurso e se posiciona em seu discurso.

Nas análises discursivas, observamos os indícios linguísticos dos sujeitosprofessores através de suas marcas registradas pela escrita, onde possibilitamos ao professor narrar-se, trazendo as marcas de sua formação, deixando-os discursivizar sobre 


\section{Revista do SELL}

v. 6 , no. 3

ISSN: $1983-3873$

a formação continuada, marcando suas posições, interpretações e identidades do saber e poder, lembrando que, ao escrever o sujeito é atravessado pelos esquecimentos 1 e 2 (acreditando ser a fonte de seu dizer e tendo a ilusão de/nas e pelas palavras tudo caberá).

Então, ao escrever, o sujeito se constitui e é constituído, podendo deixar marcas, indícios ou pistas de submissão, resistência e/ou assujeitamento (Foucault, 1983).

Escrever é um dos recursos de que podemos nos valer para inverter, ainda que precariamente, a posição passiva que experimentamos diante dos fatos e cotidiano que vivemos, dessa maneira, o sujeito pode encontrar na escrita espaço de acessos e denúncias da realidade, então, ao traçar o que é formação continuada, a escrita traz o percurso próprio do sujeito-professor, suas identidades, suas vontades, seus desejos, seus bordados e as bordas que comprimem ou desenham em seus tecidos, dando-lhes forma que podem ser puxadas pelos fios da singularidade, determinando suas especificidades e sua diferença, ou apenas amarrar esses fios ao que já está determinado e proposto.

Nesse percurso de escrita, propomos deslocamentos para que o sujeito diga, escreva e se inscreva e não apenas reescreva já-ditos, fazendo ecoar sua memória discursiva, reverberando as práticas escolares na constituição de suas identidades profissionais.

\section{ASPECTOS METODOLÓGICOS DO CORPUS E GESTOS INTERPRETATIVOS}

Na perspectiva da $A D$, consideramos a materialidade linguística no ponto em que se unem linguística, ideologia e inconsciente. Tratamos a metodologia, não como um modelo que se aplique de modo indiferenciado a todo e qualquer discurso, mas constituinte da $A D$, que é uma metodologia que se constrói num movimento contínuo entre teoria e a própria análise, num ir-e-vir constante entre o corpus e os fundamentos.

Ao longo do ano 2012, realizamos a coleta de depoimentos em um curso de formação continuada, na cidade de Ribeirão Preto, SP. Esse curso foi oferecido dentro da USP - Faculdade de Filosofia e Letras de Ribeirão Preto. Foi um curso de 160 horas, gratuito, as inscrições foram por adesão e estava aberto para a rede Municipal, Estadual e SESI.

Esses depoimentos foram feitos de maneira espontânea através de perguntas semiestruturadas, com o consentimento livre e esclarecido desses sujeitos. Podemos dizer que tais depoimentos e suas condições de produção formaram o "material bruto" (Orlandi, 1999), ou amplo "espaço discursivo" (Courtine, 1981), que deu origem ao nosso corpus. A 


\section{Revista do SELL}

v. 6 , no. 3

ISSN: $1983-3873$

partir desse espaço discursivo, selecionamos alguns recortes, entendidos aqui como "(...) fragmentos correlacionados de linguagem e situação" (Orlandi, 1987, p.87).

Desses recortes, escolhemos algumas Sequências Discursivas de Referência (SDR), (Courtine, 1981), as quais foram por nós analisadas, como mostraremos na próxima seção. Importa ressaltar que nos valemos do paradigma indiciário, tal como proposto por Carlo Ginzburg (1980). As marcas e pistas linguístico-discursivas serão por nós perscrutadas, visto que nos permitem puxar os fios do discurso (intradiscurso), que nos remetem às formações discursivas e suas respectivas formações ideológicas. Esse processo possibilitar-nos-á delinear as regularidades discursivas dos dizeres dos sujeitos.

No processo metodológico, consideraremos a relação intradiscurso e interdiscurso. A observação desse permite remeter os dizeres dos sujeitos-professores a uma filiação de dizeres, a uma memória, e a identificá-la em sua historicidade, em sua significância, mostrando seus compromissos políticos e ideológicos. Aquele fio do discurso, o intradiscurso, permite-nos notar o que está sendo dito, naquele momento dado, em determinadas condições de produção.

Como bem elucida Courtine (1981), todo dizer se encontra na confluência de dois eixos: o da memória (constituição) e o da atualidade (formulação). E é a partir desse jogo que nascem os sentidos, sempre em movimento, sempre nos escapando, posto que 0 sujeito se constitui no e pelo dizer que está historicamente filiado a determinadas redes de sentido e não a outras, ou melhor, a determinadas formações discursivas e não a outras.

Outra questão que deve ser salientada é que a $A D$ não busca alcançar a exaustividade horizontal, visto que não há discurso fechado em si mesmo, todo discurso se estabelece na relação com o anterior e aponta para outro. Temos, assim, um processo discursivo do qual recortamos e analisamos estados diferentes (Orlandi, 1999). 


\title{
Revista do SELL
}

v. 6 , no. 3

ISSN: $1983-3873$

\section{GESTOS DE INTERPRETAÇÃO: BUSCANDO OS INDÍCIOS E OS VESTÍGIOS NOS DIZERES DOS PROFESSORES.}

\begin{abstract}
Recorte 1 - Os cursos de formação continuada geralmente são bons, mas sempre são impostos. O pessoal da secretaria diz que não, mas, na realidade são sim, arrumam uns jeitinhos para nos obrigar... Até aí tudo bem. Agora o que me chateia é a qualidade desses cursos: todos eles querem ensinar o "padre-nosso para o vigário", não consideram que a gente sabe alguma coisa, não sabem que estudantes fomos, que fazemos pósgraduação, frequentamos grupos de estudo, que fazemos disciplinas como alunos especiais e ouvintes em diversas universidades, como é o meu caso. Acho que deveriam procurar saber quem é o professor pública, não somos tão desprezíveis assim. (Professor 32- Y.O.S.- 47 Anos- Ribeirão Preto).
\end{abstract}

Para iniciar nossa análise, destacamos a sequência discursiva os cursos de formação continuada geralmente são bons, mas sempre são impostos. O sujeito-professor Y.O.S. inscreve-se em formações discursivas que o levam a afirmar que os cursos de formação geralmente são bons, atestando que, na maioria das vezes, os cursos preenchem as necessidades. Observamos, aqui, a forma sujeito que é a identificação do sujeito do discurso com a formação discursiva que o domina. Entretanto ao enunciar "mas" estabelece o contraste à ideia até então posta, ele rompe e se desloca dessa formação discursiva, nesse deslocamento discursivo o sujeito-professor mostra-se resignado aos cursos que Ihes são oferecidos pelo órgão de ensino, e indica-o materialmente na conjunção adversativa "mas", que produz o efeito de sentido de contradição.

Não poderíamos deixar de mencionar que a sequência discursiva pessoal da secretaria que produz efeito de sentido de indeterminação posto que não conseguimos identificar quem é abarcado pela expressão "pessoal da secretaria", o que produz efeito de sentido de distanciamento e generalização.

Sobre o jeitinho, podemos pensar na expressão brasileira como um modo de agir, que é informal, se vale de improvisação, é flexível, "criativo", não se baseia em regras, ao mesmo tempo que pode trazer soluções para situações inesperadas. Nesse recorte os "jeitinhos" no diminutivo soam com um sentido negativo, como se o "pessoal da secretaria" tivesse driblando convenções sociais. Nesse caso, entendemos que vai ao encontro das convenções sócio-ideológicas, uma vez que a ideologia produz o efeito de evidência, de 


\section{Revista do SELL}

v. 6 , no. 3

ISSN: $1983-3873$

unidade, naturalizando o que é produzido pela história (Pêcheux, 1995). Entendemos que tal enunciado remete às formações ideológicas que naturalizam "o jeitinho brasileiro" propagado em diferentes situações, e que, em alguns casos, contrapõem-se à ordem e à lei.

Para adensar nossa discussão trazemos "Raízes do Brasil", de Sérgio Buarque Holanda em particular "O homem cordial". O autor marca o viés da antropologia que o jeitinho brasileiro se associa aos das instituições brasileiras que foram concebidas de forma coerciva e unilateral, não havendo diálogos entre governantes e governados, mas apenas imposição de leis. Tal argumentação leva-nos a pensar em um discurso autoritário marcado pelo DPE (Discurso Pedagógico Escolar) que, segundo Orlandi (1987), está sempre reproduzindo o mesmo, e não possibilita ao sujeito-professor se posicionar e nem se inserir em outras formações discursivas, para além das que estão sendo ditas.

Ainda no primeiro parágrafo, observamos, então, a palavra imposição que denuncia, e marca essa formação de professores como uma ação determinada e estabelecida, não por qualquer sujeito e sim pelo pessoal da secretaria. Podemos também, fazer emergir o sentido de imposição como aquilo que vem ao encontro da necessidade, da exigência e da obrigação em relação à formação do professor, pois, há uma conformidade, até aí tudo bem.

Se pensarmos que, na formação de professores, o sujeito-professor se posiciona como aprendiz, (re)formulando conceitos e práticas e aprimorando teorias e conhecimentos, há um deslizamento na relação de poder, pois aqui, o professor em formação é colocado e imaginado como um sujeito que não possui saber algum, posicionado como aluno que, supostamente, estaria em nível zero de conhecimento. Dessa maneira, prevalece à posição fixa de "ouvinte", e essa professora se sente incapaz, uma vez que não é dona da verdade, não domina o conteúdo apresentado, e isso a incomoda, a inquieta, pois não deixam que ela diga, escolha. Dessa maneira essa educadora perde sua voz e não coloca sua opinião. Aqui o sujeito-professor permanece apenas na condição de sujeito (d)enunciador e reprodutor de sentidos alheios, que muitas vezes não Ihe fazem sentido algum, pois se vê obrigado a inserir-se em formações discursivas com as quais não se identifica.

Ainda enuncia que esses cursos vêm apenas ensinar o padre-nosso ao vigário, fazendo emergir uma expressão popular bastante conhecida no Brasil, usada aqui para ensinar algo a uma pessoa que já sabe muito sobre o assunto trazido. Temos aqui o chamado genérico discursivo "pois não questiona o poder responsável por esse estado de 


\section{Revista do SELL}

v. 6 , no. 3

ISSN: $1983-3873$

coisas, então um genérico pode ser um acontecimento discursivo sobre outro acontecimento" (Tfouni, 2007), sendo esse professor afetado a partir de um lugar que não deslumbra nada de bom para ele, nenhum acréscimo, como se não houvesse sentido não conhecido nesse curso. Esse genérico enuncia o tempo linguístico e ideológico, cristaliza aspectos da identidade, ao mesmo tempo que marca o acontecimento enquanto equívoco.

Nesse enunciado, evidenciam-se traços do discurso pedagógico autoritário, que se faz presente nesse órgão de ensino. Mas, também, esse sentido pode se deslocar e emergir às nossas raízes, no momento da catequização, em que o ensino era imposto, fazendo ecoar legados, trazendo leitura única, uma posição discursiva apenas e reprodutora e legitimadora da instituição escolar delimitada. Nesse discurso, marca-se a imposição do pessoal da secretaria, historicizando o processo de legitimação do saber, poder e fazer. Nessa linha de argumentação, destacamos a pedagogia jesuítica caracterizada por um ensino conteudístico, livresco avaliativo e reprodutor de sentidos legitimados pelas sagradas escrituras.

$\mathrm{Na}$ última sequência Acho que deveriam procurar saber quem é o professor pública, não somos tão desprezíveis assim, observamos o sentido da verdade com efeito de lei, instalada pela voz dessa professora de que é possível que tais cursos deem suporte metodológico, teórico e prático, porém, há necessidade de tais "palestrantes" saberem quem é o professor da escola pública, há nesses dizeres denúncias e anúncios de que tais cursos não são capazes de formar o professor e, tampouco os alunos, deixando sempre em seu percurso lacunas, por não saberem quem é o professor da escola pública.

Novamente essa professora legitima o sentido que coloca teoria e prática em posições distintas e antagônicas. Essas posições e esse entendimento por parte do sujeitoprofessor marcam-se linguisticamente em forma de parafrástica desconectando teoria de prática, ecoando em forma de paráfrase, uma posição de assimetria anunciada em tais cursos de formação. Aqui, a voz que denuncia traz um efeito da memória e faz retornar ao mesmo.

Ainda na sequência discursiva não somos tão desprezíveis assim há tom de ironia, pontuando o efeito de sentido que marca o desmerecimento do outro, instalando sentidos contrários àqueles que a palavra literal expressa. Nesse momento, essa educadora recupera o sentido de alguém que sabe sobre seu fazer escolar, e traz à tona sua memória e toda sua constituição enquanto profissional, marcando suas formações e seus aprimoramentos educacionais, seu saber, poder e fazer, carregados de emoção e de insatisfação com a situação em que se encontra momentaneamente. 


\section{Revista do SELL}

v. 6 , no. 3

ISSN: $1983-3873$

No gesto de interpretação desse sujeito-professor sobre a formação continuada, ele pressupõe que esperava algo dinâmico e que fizesse sentido na prática da sala de aula, esperava estratégias e não apenas uma unidade de significação já-lá.

O professor coloca os cursos de formação no âmbito prático escolar enquanto falta, marcando o desmerecimento das secretarias e dos profissionais que ocupam a posiçãosujeito- formadores nesses cursos. Nesse recorte, concordamos com Pfeiffer (2003) quando afirma que "o problema é ideológico e não metodológico", pois tais cursos sustentam discursos em que o professor, na posição de aluno, não pode realizar interpretações, é passível de interpretação e só conseguirão atingir os ideias institucionais com técnicas e metodologias prontas e passíveis de serem apreendidas por modelos prontos, condições de produção pré-determinadas que simplificam as decodificações e apagam as diferenças entre os sujeitos-escolares, tentando linearizar os problemas, a política, a relação de poder e a ideologia.

Nessas condições de produção, a identidade do sujeito-professor é afetada negativamente, posto que não se sente acolhido, respeitado em relação à sua história, memória e percurso profissional, posto que deve se desfazer de seus "saberes da experiência" e "saberes profissionais", para seguir modelos estéreis, esvaziados de sentidos. Modelos com os quais não se identifica, visto que não fazem parte de seu interdiscurso, nem consideram os sentidos de sua memória discursiva, concernentes à sua prática pedagógica.

Recorte 2 - Os cursos da diretoria de ensino são de curta duração. É tudo curto e tem que ser porque o pobre do coitado do professor não aguenta, não suporta mais ouvir falar em tanto curso, ok, são de graça, mas de que adianta se não falam a língua da gente, se nem perguntam, nem uma unicazinha vez que seja o que se passa na sala de aula, o que de fato acontece lá dentro. Estou aproveitando este espaço para desabafar porque eu e minhas amigas, e posso te dizer que tenho muitas, nós não suportamos mais tantos cursos e todos eles tão longe do que de fato precisamos (sujeito-professor 25- A.S.C. - 46 anos-Ribeirão Preto)

Logo no primeiro parágrafo do recorte, a materialidade linguística nos deixa perceber os efeitos de sentidos sobre os cursos da diretoria de ensino, ou seja, o curso imposto, prédeterminado, sem diálogo ou sugestão dos professores. Assim, de um lado temos um 
programa pré-definido pela diretoria de ensino e do outro a professora, inscrita numa outra área do saber, numa outra formação discursiva, mesmo não aprovando, a princípio, o curso oferecido, acaba por se submeter à hierarquia, participando de um programa com regras definidas. Há um deslocamento de posições sociais históricas, pois aqui o professor não detém todo saber e ocupa a posição de aprendiz, de aluno.

Ao repetir os cursos são de curta duração, entendemos que há marcas, sentidos naturalizados sobre a formação continuada de professores, onde há a denúncia de que o mesmo precisa ser curto, porque o tempo disponibilizado pelo professor é mínimo, levando em consideração a necessidade de se trabalhar até mais que um período para sobreviver. O sujeito-professor 25 A.S.C. inscreve-se em formações discursivas que indicam autopiedade, afinal, esse professor é pobre coitado e não aguenta, não suporta mais ouvir falar em tanto curso. O argumento que sustenta tal vitimização é o de que o óbvio marca esses cursos, ou seja, o que lhes é apresentado parece não afetá-lo, nem lhe fazer sentido algum.

Interessante observar os efeitos de sentido proporcionados pelos significantes aguenta e suporta. Segundo nossos gestos interpretativos, parece que indicam sentimentos de exaustão diante do que o órgão de ensino acredita ensinar e transmitir para o sujeito-professor. Nessa perspectiva, Imbérnon (2010, p.68) afirma que as mudanças ainda são lentas, pois a manutenção dessas instituições, e estruturas legitimam, e facilitam a continuação de um trabalho isolado, não existe diálogo sobre o que acontece, e a troca é fictícia.

Na sequência discursiva ok, são de graça, mas de que adianta se não falam a língua da gente, se nem perguntam, nem uma unicazinha vez que seja o que se passa na sala de aula, observamos que se instala a posição-sujeito em que o sentido do ensinoaprendizagem, apesar de ser de graça, está restrito ao ato de trazer apenas teorias e reflexões intelectuais descontextualizadas da realidade, em que se insere essa professora, assim, não vem ao encontro da labuta diária e cotidiana, pois as línguas não se cruzam na aplicabilidade da sala de aula.

O recorte, não falam a língua da gente, nos leva a pensar na linguagem que não é transparente, nos dizeres que não são apenas mensagens a serem decodificadas, portanto, não são regularizadas gramaticalmente, mas estão em movimento entre sujeitos sóciohistóricos e ideológicos, com individualidades intra e interdiscursiva e com memórias culturais e/ou próprias, assim, a palavra não possui um único sentido, por isso não falam a língua da gente. 


\section{Revista do SELL}

v. 6 , no. 3

ISSN: $1983-3873$

Esse recorte pode também ser analisado pelo viés das relações de poder em que realmente os órgãos institucionais não desejam que os sujeitos-professores entendam tais enunciados de ideias, conceitos e dizeres, assim os efeitos de sentido produzidos pelo discurso trazem as palavras carregadas das formações ideológicas, marcando o discurso autoritário, em que a função precípua desse tipo de discurso é a inculcação (Orlandi, 1987).

Maingueneau (2005) ainda acrescenta que a interdiscursividade é um conjunto de discursos que mantém uma relação discursiva entre si, ou seja, termos de outras esferas ou discursos atuando numa relação conflituosa (ou não). Dessa maneira, nessa situação, nesse espaço discursivo não houve troca, o campo discursivo não foi atingido, ficou restrito ao formador e não atingiu esse professor, permitindo dispersão, não integrando os enunciados. Assim, esse recorte dialoga com o primeiro recorte e mostra-nos mais uma vez que o curso vem imposto e não há preocupação desse órgão de ensino com o interdiscurso e com a memória discursiva do sujeito-professor. Ao desconsiderar esses elementos, o órgão de ensino afasta-se do sujeito-professor visto que esses elementos fazem circular sentidos que não reverberam, não ecoam, não afetam o sujeito-professor inscrito em outras formações discursivas.

A professora ainda discursiviza: Estou aproveitando este espaço para desabafar porque eu e minhas amigas e posso te dizer que tenho muitas..., o espaço proposto e aberto, aqui, deu a essa professora a voz que estava calada, por isso, ela está aproveitando verbo no gerúndio, que nos dá pistas de que nesse momento essa professora subverte a ordem, a regra e a estabilidade em que se submete e, nesse espaço, esse sujeito denuncia e desabafa, essa professora vê uma oportunidade para reiterar a insatisfação, por isso ela se manifesta, se expõe e se sente (des)impedida de assumir qualquer responsabilidade que possa vir acontecer na prática da sala de aula. Ela ainda denuncia que esse desabafo não é só dela, mas das muitas amigas, e, ao deslocar o eu para nós, faz ecoar as vozes daquelas professoras que compartilham de uma ideia, de um ideal e de um interdiscurso.

Ao escrever o sujeito é atravessado por dizeres e fazeres e, em seu discurso, há imbricada uma "escritura de si" (Foucault, 1992), que traz em seu bojo uma concepção do inconsciente, estruturada na linguagem, que, por sua vez, é marcada, tecida e bordada na subjetividade. Dessa maneira, a escrita é científica, mas a história individual do sujeito é subjetiva.

Na sequência discursiva nós não suportamos mais tantos cursos e todos eles tão longe do que de fato precisamos, constatamos uma voz que interdita, que traz condensação de sentidos, de que esses cursos não servem, reforçando uma verdade com 


\section{Revista do SELL}

v. 6 , no. 3

ISSN: $1983-3873$

efeito de lei, instalada pela voz dessa professora, como se dissesse que esses cursos que deveriam dar suporte, não suportamos! Há aqui uma denúncia e o distanciamento entre o conhecimento acadêmico e o prático, esses cursos estão longe de ser o que elas realmente necessitam, culpabilizando então a diretoria de ensino pelo fracasso do ensinoaprendizagem, não marcando a defasagem que poderia haver na formação do professor uma vez que esses não falam a língua da gente.

Nesse recorte, a formação continuada não está dentro das normas e da rotina dessa professora, assim, não é aceita como tal. O trecho acima reforça o universo semanticamente estabilizado, instalado pela voz desse sujeito-professor, marca sítios de significância e historiciza o processo de produção de sentido sobre a formação continuada.

O discurso autoritário, como vimos procurando mostrar, é discursivizado pelos sujeitos-professores, a partir de sentidos que evocam críticas negativas aos aspectos autoritários dentro de situações por eles vivenciadas em formação continuada, que pressupõem e colocam o sujeito-professor na condição de um profissional que não possui saberes profissionais acumulados, que não possibilita ao sujeito inserir-se em formações discursivas que não aquelas valorizadas pela instituição escolar, muito menos ocupar lugares a partir dos quais poderia atribuir e produzir sentidos, segundo própria memória discursiva.

Já as situações de ensino que não promovem a emergência de processos identificatórios nem em relação ao que é transmitido, nem em relação aos "formadores dos professores", promovem descontentamento e distanciamento do sujeito em relação a esses cursos, que poderiam constituir-se em "espaços discursivos (Assolini, 2013) que thes possibilitassem narrar, pensar e, se necessário, ressignificar os seus saberes e fazeres pedagógicos". Para nós, é imprescindível que o sujeito-professor possa ter direito e usufruir plenamente desses espaços, que poderiam the assegurar oportunidades e condições favoráveis de produção para (se) dizerem, fator importante para a construção de uma identidade profissional marcada pela posição de sujeito capaz de pensar, argumentar e discutir o que lhe apresentado como "óbvio" e natural. 


\section{Revista do SELL}

v. 6 , no. 3

ISSN: $1983-3873$

\section{ALGUMAS CONSIDERAÇÕES PARCIAIS}

Esta investigação em andamento oportunizou olharmos a formação docente, buscando compreender como o docente se formou (inicialmente) e se reforma (continuamente), dentro dos movimentos possíveis de seus processos profissionais, que não estão acabados, estáticos e nem prontos, estão sempre em movimento, se construindo pelas experiências e interações com os alunos, as instituições, a sociedade e os outros.

Compreendemos que, também, nas situações vivenciadas em processos de formações continuadas, os professores podem deixar os indícios, as marcas, as consequências e as implicações de como essa nem sempre são, de fato, formativas, podendo, como mostramos ao longo deste artigo, afetar negativamente a construção da identidade profissional docente como apresentado nos recortes por nós analisados, demonstrando-nos que os professores não se identificam com o que lhes é proposto ou sugerido nesses cursos.

A formação continuada ainda necessitará de muitas investigações, a fim de efetivarmos mudanças necessárias e urgentes, como possibilidades de mudanças das condições que ainda hoje se (re)fazem.

\section{REFERÊNCIAS}

ALMEIDA, M. I. de. Formação do Professor do Ensino Superior: desafios e politicas institucionais - $1^{\text {a }}$ ed. - São Paulo: Cortez, 2012. - (Coleção docência em formação: Ensino Superior/ coordenação Selma Garrido Pimenta)

ASSOLINI, F. E. P. Diferentes Linguagens no contexto escolar: Questões conceituais e apontamentos metodológicos (org) - páginas 33-51, 2013.

RIVAS, N.P.P. Leituras e memórias de sentidos: repercussões na prática pedagógica escolar. In: 34ª Reunião Anual da ANPED - Educação e Justiça Social, 2011, Natal/RN. Educação e Justiça Social. Rio de Janeiro: ANPED, 2010.v.01. p.1-17. 
COURTINE, Jean-Jacques. [1981]. Análise do Discurso: o discurso comunista endereçado aos cristãos. Tradução de Bacharéis em Letras pela Universidade Federal do Rio Grande do Sul. São Carlos: EdUFSCar, 2009.

FOUCAULT, M. A arqueologia do saber. Rio de Janeiro: Forense Universitária, 1969/1983. 19

O que é um autor? Trad. Antônio Fernando Cascais, Eduardo Cordeiro. Rio de Janeiro: Vega, 1992.

GREGOLIN, M. do R. V. Formação Discursiva, Redes de Memória e Trajetos Sociais de Sentido: Mídia e produção de identidades - Araraquara - São Paulo, 2009. (http://www.uems.br/padadi/rosario.html)

GINZBURG, C. Sinais: raízes de um paradigma indiciário. In: Mitos, emblemas, sinais: morfologia e história. São Paulo: Companhia das Letras, 1980.

IMBERNÓN, F. Formação Continuada de Professores. Porto Alegre: Artmed, 2010.

MAINGUENEAU, D. Análise de textos de comunicação. São Paulo: Cortez, 2005.

NÓVOA, A. A solução pode estar no trabalho de pensar o trabalho. Portugal: número zero, abril: 2004. Entrevista conduzida por João Rita.

ORLANDI, E. P. Nem escritor, nem sujeito: autor. In: Leitura: teoria e prática. Campinas: Mercado Aberto, n. 9, p. 13-7, jun/1987.

A linguagem e seu funcionamento: as formas do discurso. Campinas, SP: Pontes; 1996.

Paráfrase e Polissemia: a fluidez dos limites do simbólico. Rua (Revista do Núcleo de Desenvolvimento da Criatividade). №4. Campinas: Editora da Unicamp, 1999.

A leitura e os Leitores. (org.) Pontes. Campinas. S, 2003. 
Análise do discurso: princípios e procedimentos. São Paulo: Pontes, 2005.

PÊCHEUX, M. (1969). Por uma Análise Automática do Discurso: uma Introdução à Obra de Michel Pêcheux. F.Gadet e T.Hak (orgs.). Unicamp, 1990

Semântica e discurso: uma crítica à afirmação do óbvio. Campinas: FUCAMP - Fundação de Desenvolvimento da UNICAMP, 1975/1995.

PFEIFFER, C. C. Educação a distância, Mídia e Reciclagem. In: GUIMARAES E. (Org). Produção e circulação do conhecimento: política, ciência e divulgação. v.2. Campinas, SP. Pontes Editores, 2003. (p.31-42).

TARDIF, M. Saberes docentes e formação profissional. Tradução de Francisco Pereira. Petrópolis: Vozes, 2002.

TFOUNI, L.V. "Entra burro; sai ladrão": O imaginário sobre a escola materializado nos genéricos. In: Linguagem em (Dis)curso - LemD, Tubarão, v.7, n.2, p.293-311, mai/ago 2007. 